University of New Hampshire

University of New Hampshire Scholars' Repository

Kinesiology Scholarship

Kinesiology

$1-1-2009$

\title{
Initial neuromuscular performance in older women influences response to explosive resistance training
}

Dain P. LaRoche

University of New Hampshire, Durham, dain.laroche@unh.edu

Follow this and additional works at: https://scholars.unh.edu/kinesiology_facpub

Comments

This is an Author's Original Manuscript of an article published by IOS Press in Isokinetics and Exercise Science in 2009, available online: https://dx.doi.org/10.3233/IES-2009-0354

\section{Recommended Citation}

D.P. LaRoche. (2009) Initial neuromuscular performance in older women influences response to explosive resistance training. Isokinetics and Exercise Science. 17(4): 197-205.

This Article is brought to you for free and open access by the Kinesiology at University of New Hampshire Scholars' Repository. It has been accepted for inclusion in Kinesiology Scholarship by an authorized administrator of University of New Hampshire Scholars' Repository. For more information, please contact

Scholarly.Communication@unh.edu. 
Published in final edited form as:

Isokinet Exerc Sci. 2009 January 1; 17(4): 197.

\title{
Initial neuromuscular performance in older women influences response to explosive resistance training
}

\author{
Dain P. LaRoche* \\ Department of Kinesiology, University of New Hampshire, Durham, NH, USA
}

\begin{abstract}
The purpose of the study was to identify both demographic and neuromuscular traits that characterize successful or unsuccessful adaptation to resistance training in older women. Twelve, older women underwent electrically evoked muscle twitches for the knee extensors; and performed maximal, voluntary, isometric knee extensions, followed by eight weeks of resistance training. Prior to training nonresponders had $67 \%$ higher twitch peak torque than responders $(0.29 \pm 0.05$ vs. $0.18 \pm 0.06$ $\mathrm{Nm} \cdot \mathrm{kg}^{-1}$ respectively), $64 \%$ higher twitch rate of torque development (RTD) (3.96 $\pm 0.47 \mathrm{vs.} 2.42$ $\left.\pm 0.62 \mathrm{Nm} \cdot \mathrm{s}^{-1} \cdot \mathrm{kg}^{-1}\right), 51 \%$ higher voluntary peak torque $\left(1.86 \pm 0.40 \mathrm{vs.} 1.23 \pm 0.33 \mathrm{Nm} \cdot \mathrm{kg}^{-1}\right), 101 \%$ greater RTD $\left(9.43 \pm 1.52\right.$ vs. $\left.4.70 \pm 2.40 \mathrm{Nm} \cdot \mathrm{s}^{-1} \cdot \mathrm{kg}^{-1}\right), 86 \%$ greater impulse $(0.13 \pm 0.01$ vs. 0.07 $\pm 0.03 \mathrm{Nm} \cdot \mathrm{s} \cdot \mathrm{kg}^{-1}$ ) and $27 \%$ faster motor time ( $80 \pm 13 \mathrm{vs.} 109 \pm 34 \mathrm{~ms}$ ), (all $\left.\mathrm{P}<0.05\right)$. Following training, responders showed an $11 \%$ increase in twitch peak torque over baseline $(0.18 \pm 0.06$ to 0.20 $\left.\pm 0.05 \mathrm{Nm} \cdot \mathrm{kg}^{-1}\right), 15 \%$ increase in voluntary peak torque $\left(1.23 \pm 0.33\right.$ to $\left.1.41 \pm 0.36 \mathrm{Nm} \cdot \mathrm{kg}^{-1}\right), 47 \%$ increase in RTD $\left(4.70 \pm 2.40\right.$ to $\left.6.93 \pm 2.02 \mathrm{Nm} \cdot \mathrm{s}^{-1} \cdot \mathrm{kg}^{-1}\right), 43 \%$ increase in impulse $(0.07 \pm 0.03$ to $0.10 \pm 0.04 \mathrm{Nm} \cdot \mathrm{s} \cdot \mathrm{kg}^{-1}$ ), and $26 \%$ increase in rate of EMG rise (886 \pm 214 to $1116 \pm 102 \%$ $\left.\mathrm{pEMG} \cdot \mathrm{s}^{-1}\right)($ all $\mathrm{P}<0.05)$. Initially higher muscle mass and contractility, coupled with greater neural drive, likely explains why older women with good muscle performance seem to have a lower capacity for improvement than women with low initial levels of performance.
\end{abstract}

\section{Keywords}

Electromyography; aging; training adaptations; strength; power; nervous activation; reaction time

\section{Introduction}

Muscular power and rate of joint torque development (RTD) are two closely related variables that are associated with functional ability in older individuals and have been shown to decline with age $[4,12,28]$. Preserving or improving older adults' capacity to rapidly generate muscle force through physical training is an important and widespread therapeutic practice with the goal of maintaining independence, mobility, and reducing fall risk. The efficacy of resistance training to increase the rate of muscle force development, and subsequently the rate of joint torque development, appears to vary across studies with some showing marked improvements $[6,7,19]$ while others show little or no effect $[9,15,26]$. Disparities between studies may be due to a number of methodological factors including the sample chosen, muscle group studied, duration of the training intervention, contraction type (e.g. lengthening, shortening, or isometric), velocity of contraction, and total work performed during training.

(C) 2009 - IOS Press and the authors. All rights reserved

*Address for correspondence: Dain P. LaRoche, Ph.D., 124 Main Street, Durham, NH 03824, USA. Tel.: +1 603 862 4859; Fax: +1 603 862 0154; Dain.LaRoche@unh.edu.. 
Studies showing improved muscle power and rate of force development include those by Earles et al. [6], Ferri et al. [7], and Newton et al. [19]. Earles et al. [6] compared a self-paced walking program to high-velocity lower extremity resistance exercise in older men and women demonstrating a $22 \%$ increase in leg press power in the power training group $(273 \pm 115$ to $337 \pm 156 \mathrm{~W}$ ) with no improvement seen in those in the walking group ( $277 \pm 70$ to $256 \pm 88$ $\mathrm{W})$. In response to traditional resistance training using machine-based leg press and calf raise exercises, Ferri et al. [7] showed a $24.1 \pm 6.3 \%$ increase in power for the knee extensors and a $33.1 \pm 10.9 \%$ increase in plantar flexor power in older men. Also studying men, Newton et al. [19] had participants perform squat, knee extension, and knee flexion exercises three days per week for ten weeks. They noted that older men significantly increased power during squat jumps by $7-36 \%$ across a variety of loads.

In contrast to these studies showing the ability of older adults to gain power with resistance training, a number of other studies have shown limited gains following training. Skelton et al. [26] reported a wide-ranging response to resistance training for leg extensor power in older women. Despite an $18 \%$ increase in power in trained subjects $(61.7 \pm 23.0$ to $79.3 \pm 18.7 \mathrm{~W})$, the improvement was not statistically different from non-training controls (4\% increase from $69.8 \pm 31.4$ to $71.2 \pm 31.4 \mathrm{~W}$ ) likely due to a high degree of variation in the training response. Hakkinen et al. showed no effect of resistance training on muscle rate of force development (RFD) in older men reporting that the initial RFD $\left(2819 \pm 398 \mathrm{~N} \cdot \mathrm{s}^{-1}\right)$ was unaltered by 10 weeks of resistance training despite a 17\% increase in maximal isometric knee extension force $(976 \pm 168$ to $1132 \pm 218 \mathrm{~N})$ [9]. A recently completed investigation in our laboratory [15] showed only modest improvements in knee extensor RTD in older women in response to resistance exercise. Specifically, those that performed an eight-week isokinetic strength and power training program demonstrated improved RTD $(+9 \%$, from $7.17 \pm 0.89$ to $7.83 \pm 0.69$ $\mathrm{Nm} \cdot \mathrm{s}^{-1} \cdot \mathrm{kg}^{-1}$ ) that was not different from non-training controls ( $+8 \%$, from $6.24 \pm 0.80$ to 6.73 $\pm 0.73 \mathrm{Nm} \cdot \mathrm{s}^{-1} \cdot \mathrm{kg}^{-1}$ ) and was significantly less than seen in young subjects $(+34 \%$, from 9.13 \pm 0.92 to $12.27 \pm 0.87 \mathrm{Nm} \cdot \mathrm{s}^{-1} \cdot \mathrm{kg}^{-1}$ ). The response to training was highly variable across older participants with training-induced changes in RTD ranging from $-27 \%$ to $+142 \%$. This paper is a continued analysis of that project that attempts to explain the variation in the training response.

Therefore, the purpose of this study was to identify both demographic and neuromuscular subject traits that characterized the successful or unsuccessful adaptation to resistance training in older women. The variable gains in the rate of muscle force development between individuals and across studies questions the role of gender as a modifier of strength and power gains and what demographic, neuromuscular, experiential, and physiological factors influence older adults' response to resistance training. This research is important in that it may be used to develop strength and power training protocols that are effective for a wider range of older adults. The author hypothesized that age, training history, prevalence of disease (e.g. heart disease, diabetes), and baseline nervous and muscular performance are likely predictors of gains in joint RTD following training.

\section{Methods}

\subsection{Participants}

This study was performed on twelve, independent, older women (73.0 $\pm 7.2 \mathrm{yr}$, Table 1) with unrestricted mobility who underwent eight weeks of isokinetic resistance training designed to increase maximal strength and power. To document activity level, a historical activity interview was used to estimate the average volume of physical activity for the previous ten years and was reported in MET $\cdot$ hours $\cdot$ week $^{-1}[2,13]$. This method of quantifying the volume of physical activity has been validated for use in elderly women [29]. Additionally, participants completed a questionnaire to determine the prevalence of heart disease, cerebral vascular accident, 
hypertension, osteoporosis, arthritis, joint replacement, ligamentous injury, diabetes, peripheral vascular disease, peripheral neuropathy, and prescription medication use. Each participant's current prevalence of each condition was recorded (has $=1$, does not have $=0$ ) and the number of reported health complications for each participant was totaled as a global measure of health status (score of $0=$ best health, score of $11=$ worst health). The project, including its risks and benefits, was explained to the participants who gave their written informed consent. Institutional Review Board approval for research involving human subjects was secured from the college's Human Subjects Institutional Review Board.

\subsection{Procedures}

Prior to the completion of eight weeks of isokinetic resistance training for the knee extensors (described below), and following a familiarization day where participants practiced the reaction task and maximal voluntary contractions, each participant underwent an analysis of her current level of neuromuscular function. This assessment included measures of: electrically evoked twitch torque, twitch RTD, and twitch rate of relaxation; as well as measures of total reaction time, premotor time, motor time, voluntary peak muscle torque, voluntary RTD, contractile impulse, the rate and magnitude of nervous activation of muscle, and antagonist coactivation. The women then completed eight weeks of resistance training, and all measures were repeated following training.

\subsection{Electrically evoked muscle twitch}

To record knee extensor torque, a HUMAC Norm Isokinetic Dynamometer (CSMI, Stoughton, Massachusetts, USA) was integrated with a BIOPAC MP30 data acquisition system (Goleta, California, USA). Participants were fitted to the dynamometer in a seated position with a hip angle of 90 degrees and knee angle of 105 degrees (full knee extension equal to 180 degrees). Prior to muscle stimulation, the area over the medial aspect of the dominant thigh was cleaned and two $7 \times 12.7 \mathrm{~cm}$ stimulating electrodes (Chattanooga Group, Hixson, TN, USA) were applied 10 and $25 \mathrm{~cm}$ proximal to the distal insertion of the quadriceps tendon centered over the rectus femoris muscle. To assess muscle function independent of nervous innervation, a Digitimer DS7AH muscle stimulator was used (Digitimer Ltd, Hertfordshire, England) to elicit electrically evoked muscle twitches beginning with a single square wave pulse of $200 \mu$ s in duration at $400 \mathrm{v}$ and $0.1 \mathrm{amp}$, and was increased by $0.1 \mathrm{amp}$ until a plateau occurred in the twitch torque. The single pulse reduced the subject discomfort associated with tetanic contractions but elicited submaximal muscle forces. Therefore all electrically evoked twitch torques are reported as peak instead of maximal. Force data were sampled at $1 \mathrm{kHz}$ from the analog-out auxiliary port of the dynamometer, low-pass filtered $(30 \mathrm{~Hz})$ and smoothed using a 50 sample moving average.

\subsection{Reaction task}

Participants remained in the same position on the dynamometer following muscle stimulation and were asked to perform a maximal voluntary isometric knee extension as quickly as possible following a visual stimulus. The surface electromyogram (EMG) and knee extensor torque were recorded simultaneously with an event marker corresponding to the visual stimulus. Disposable, $1 \mathrm{~cm}$ in diameter, silver silver-chloride, wet gel electrodes (Vermed, Inc., Bellows Falls, Vermont, USA) were placed over the medial aspect of the rectus femoris and biceps femoris muscles $10 \mathrm{~cm}$ proximal to their insertions with an inter-electrode distance of $20 \mathrm{~mm}$. A grounding electrode was placed over the proximal head of the fibula. EMGs from both the quadriceps and hamstring muscle groups were sampled at $1 \mathrm{kHz}$, band-pass filtered (30-500 $\mathrm{Hz}$ ), and smoothed using a 250 sample moving average using data acquisition software (BIOPAC Pro software, Goleta, California, USA). Force data were recorded as per the electrically evoked contractions. Each participant performed four contractions, each lasting 
approximately two seconds, and the mean scores for the last three trials were used for analysis. Participants rested for 60 seconds between trials.

\subsection{Data processing}

BIOPAC Pro software (Goleta, California, USA) was used to calculate dependent measures offline. RTD for both the electrically evoked twitch and the reaction task was computed by taking the peak in the instantaneous rate of change of the torque-time curve in which the rate of change was calculated over overlapping, 50-point segments. Peak torque for both the electrically evoked twitch and reaction task was recorded as the greatest torque achieved. The maximal rate of relaxation for the electrically evoked twitch was calculated by taking the minimum value in the instantaneous rate of change of the torque-time curve in which the rate of change was calculated over overlapping, 50-point segments. For the voluntary contractions, the contractile impulse from the onset of force production until $200 \mathrm{~ms}$ was obtained by integrating the torque-time curve over this period. Reaction time was defined as the time between the visual stimulus and the beginning of force production. Premotor time was defined as the time between the stimulus and the beginning of the EMG burst. Motor time was defined as the time between the beginning of the EMG burst and the beginning of force development.

The measures of neural stimulation were taken from surface EMGs. Rate of EMG rise was measured as the peak in the instantaneous rate of change of the EMG-time curve in which the rate of change was calculated from overlapping 50 point segments. It was normalized to the EMG seen at peak torque (pEMG) and expressed as percent of pEMG per second. The magnitude of neural stimulation at the onset of contraction was computed as peak EMG amplitude from the upslope of the force vs. time curve and was also normalized to pEMG and expressed as a percentage. To assess the level of coactivation of the antagonist muscle group, the peak EMG amplitude from the hamstring muscle group was recorded during the knee extension task. It was then normalized to the peak EMG amplitude of a maximal voluntary isometric contraction of the hamstrings recorded prior to the knee extension trials.

\subsection{Training}

Subjects performed eight weeks of explosive isokinetic resistance training for the knee extensors at angular velocities of $45 \mathrm{deg} \cdot \mathrm{s}^{-1}$ (low velocity/high load) and $200 \mathrm{deg} \cdot \mathrm{s}^{-1}$ (high velocity / low load). The high load exercise was focused on increasing maximal strength while the high velocity exercise was focused on increasing joint RTD. All training was completed on the isokinetic dynamometer using only shortening contractions. The training was completed at a frequency of three times per week, involved three sets of eight repetitions for each velocity, was performed separately for each leg, and a one-minute rest period was given to the subjects between each set. Although testing was only performed on the dominant leg, training was performed for each leg to prevent the development of strength imbalances over time.

\subsection{Statistical methods}

Following training, the women were separated into responders (R) and nonresponders (NR) based on gains in knee extension RTD following resistance training in comparison to twelve age-matched controls ( $73.7 \pm 4.6 \mathrm{yr})$. Because improvement in RTD was a focus of the study, since it is strongly tied to functional performance, and because the older women showed a diminished ability to improve RTD in comparison to young [15], this variable was chosen to distinguish between R and NR. Due to repetition of the strength assessment task, controls improved RTD by $8 \%$ at follow up so women in the training group with a change in RTD that was less than controls $(<8 \%)$ were classified as NR while those that had a greater change (> $8 \%$ ) were classified as R. Differences in means between groups for strength, RTD, impulse, timing and magnitude of nervous activation, and subject descriptive variables were assessed using the Kruskal-Wallis Analysis of Variance (ANOVA) test and differences within groups 
over time were assessed using a Wilcoxon Signed Rank test. These non-parametric tests were chosen because of the inclusion of ordinal scale variables, the small sample size, and a lack of normal distribution for some variables (four of the dependent variables failed the homogeneity of variance test). Statistical significance was set at $\mathrm{P}<0.05$ for all comparisons.

\section{Results}

The efficacy of the resistance training program in comparison to nontraining controls and young women has been previously reported [15]. In this analysis of the variability of the training response in older women, there were no statistically significant differences between $\mathrm{R}$ and NR for any of the subject demographics including age, body mass index (BMI), total number of health complications, or the volume of physical activity (Table 1). Prior to resistance training, NR exhibited $67 \%$ higher knee extension peak twitch torque $\left(0.30 \pm 0.05 \mathrm{Nm} \cdot \mathrm{kg}^{-1}\right)$ than $\mathrm{R}\left(0.18 \pm 0.06 \mathrm{Nm} \cdot \mathrm{kg}^{-1}, \mathrm{P}<0.05\right)$ and $64 \%$ higher twitch RTD $(3.96 \pm 0.47$ $\left.\mathrm{Nm} \cdot \mathrm{s}^{-1} \cdot \mathrm{kg}^{-1}\right)$ than $\mathrm{R}\left(2.42 \pm 0.62 \mathrm{Nm} \cdot \mathrm{s}^{-1} \cdot \mathrm{kg}^{-1}, \mathrm{P}<0.05\right.$, Fig. 1). Although training significantly increased peak twitch torque in $\mathrm{R}(11 \%)$, and reduced the magnitude of the differences between groups, NR still had enhanced muscle twitch performance post-training (Table 2). Of the reaction time measures, at baseline, only motor time was significantly faster $(27 \%$, ) in NR $(80 \pm 13 \mathrm{~ms})$ compared to $\mathrm{R}(109 \pm 34 \mathrm{~ms}, \mathrm{P}<0.05)$ with no differences between groups post-training (Table 2). Prior to training, for the voluntary force measures, NR had $51 \%$ greater knee extension peak torque $\left(1.86 \pm 0.40 \mathrm{Nm} \cdot \mathrm{kg}^{-1}\right)$ than $\mathrm{R}\left(1.23 \pm 0.33 \mathrm{Nm} \cdot \mathrm{kg}^{-1}\right), 101 \%$ greater RTD $\left(\mathrm{NR}=9.43 \pm 1.52 \mathrm{Nm} \cdot \mathrm{s}^{-1} \cdot \mathrm{kg}^{-1}, \mathrm{R}=4.70 \pm 2.40 \mathrm{Nm} \cdot \mathrm{s}^{-1} \cdot \mathrm{kg}^{-1}\right)$ and $86 \% \cdot$ higher impulse ( $\mathrm{NR}=0.13 \pm 0.01 \mathrm{Nm} \cdot \mathrm{s} \cdot \mathrm{kg}^{-1}, \mathrm{R}=0.07 \pm 0.03 \mathrm{Nm} \cdot \mathrm{s} \cdot \mathrm{kg}^{-1}$ ) (all $\mathrm{P}<0.05$, Fig. 2). Following training, NR exhibited little change in RTD and impulse but R made improvements (47\% and $43 \%$ respectively), that eliminated the statistical difference between groups for these measures (Table 2). Similarly, peak torque increased significantly over time in R (15\%, P < 0.05 ) but did not for NR. Both before and after training there were no statistical differences between groups in measures of nervous activation but $\mathrm{R}$ experienced a significant increase in rate of EMG rise $(26 \%)$ while NR had a significant decrease in this variable $(-29 \%)(\mathrm{P}<0.05$, Table 2 and Fig. 3).

\section{Discussion}

This study examined baseline demographic and neuromuscular performance factors that were characteristic of older women who either responded or did not respond well to resistance training exercise. The major identifying aspects were initial muscle twitch performance, voluntary peak torque, RTD, impulse, motor time and nervous drive to the muscle. The NR appear to be high-functioning older women whose initial strength, power, nervous activation and reaction time were similar to reported scores of women 49 years younger [15]. The prevalence of disease, age, anthropometric measures, and the volume or type of reported physical activity were not related to the magnitude of power gains following muscle power training.

It was hypothesized that $\mathrm{R}$ would have been in poorer physical condition than NR and that they would be older, have a higher body mass and BMI, would have a greater prevalence of disease, and that they would be less physically active than NR but this was not supported by the results of this study. The responders did demonstrate a trend for greater body mass and BMI that may have influenced the response to training. The role of fat and lean mass in resistance training adaptations should therefore be further studied in a larger sample. There were no differences between groups in the total volume of activity reported nor when separated into strength or aerobic activity despite a nonsignificant trend for greater strength activity in R. Because the activity history was averaged over ten years, it is possible that at the time of the study the NR were engaged in greater levels of physical activity than R. Additionally, the intensity of the 
reported activity could have varied from the estimates used for analysis and those that performed greater volume or intensity of exercise would likely have gained less from training than their more sedentary counterparts.

Of the reaction time measures, only motor time was significantly different between groups prior to training. The slower motor time exhibited by $\mathrm{R}$ is likely indicative of inefficient excitation-contraction coupling including slowed calcium release or reuptake from the sarcoplasmic reticulum and decreased activity of metabolic enzymes such as creatine kinase and actomyosin ATPase [11,21,24]. Alternatively, the slower motor time may have been due to reduced musculotendinous stiffness in $\mathrm{R}$ as a consequence of a smaller muscle crosssectional area, resulting in less immediate transfer of force from the muscle to the bone [16].

The electrically evoked muscle twitch offers insight into muscle quantity and quality at the tissue level in the absence of nervous stimulation and its magnitude has been associated with longitudinal changes in muscle cross sectional area [18]. Prior to training, muscle peak twitch torque and twitch RTD were markedly lower in R than in NR suggesting reduced muscle mass or specific force (per kilogram of muscle) in this group (Table 2). Following training, $\mathrm{R}$ experienced an $11 \%$ increase in peak twitch torque that narrowed the gap in performance between R and NR for this variable. The well-documented selective atrophy of type II (fast) muscle fibers with aging may explain the initially low levels of twitch peak torque and RTD in the $\mathrm{R}$ and the differential response to training between participants [5]. Whether by nutrition, physical activity, or genetics, the non-responding group may have been able to maintain muscle mass, normal fiber type distribution, and muscle physiology enhancing their performance and making them less susceptible to training-induced improvements. Furthermore, the age-related decline in sarcoplasmic reticulum function seen in muscle may have occurred to a greater extent in R than NR [17]. Thus, the improved twitch performance seen in the R may be partially explained by increased sarcoplasmic reticulum volume, enhanced calcium release, as well as by the muscle hypertrophy seen following intense training $[10,20]$.

Initially, NR exhibited significantly greater voluntary strength (51\% higher than R), RTD (101\% higher) and impulse ( $86 \%$ higher), but $\mathrm{R}$ were able to mitigate the differences following training. This is of great importance as these measures of strength and power are highly related to the performance of activities of daily living, the maintenance of independence and fall risk, and, this research shows that they are trainable in a low-functioning sample of older women $[1,3,22,26,27]$. The diminished muscle twitch performance and motor time seen in $\mathrm{R}$ suggest that they had initially lower muscle mass, impaired excitation-contraction coupling, and reduced contraction velocity that help explain the similarly poor performance during voluntary contraction. In contrast, the NR had an initially greater level of muscle performance, equivalent to that of women in the third decade of life, that was not trainable in this study [15]. In fact, when compared to similarly aged women (maximal knee extensor torque $\approx 1.67 \mathrm{Nm} \cdot \mathrm{kg}^{-1}$ ) in a study by Hakkinen et al. [8], prior to training the NR in this study had greater initial knee extensor torque $\left(1.86 \mathrm{Nm} \cdot \mathrm{kg}^{-1}\right)$ whereas the $\mathrm{R}$ in this study had lower performance (1.23 $\mathrm{Nm} \cdot \mathrm{kg}^{-1}$ ) than Hakkinen's subjects. In comparison to a previous investigation from our laboratory that compared low active elderly women to high active elderly women [14], the NR in this study had equivalent peak knee extensor torque $\left(1.86 \mathrm{Nm} \cdot \mathrm{kg}^{-1}\right)$ and RTD $(9.43$ $\left.\mathrm{Nm} \cdot \mathrm{s}^{-1} \cdot \mathrm{kg}^{-1}\right)$ as older women who were actively training for and partaking in competitive sports $\left(1.82 \mathrm{Nm} \cdot \mathrm{kg}^{-1}\right.$ and $9.4 \mathrm{Nm} \cdot \mathrm{s}^{-1} \cdot \mathrm{kg}^{-1}$ respectively). At the onset of this investigation, the NR were clearly functioning at a high level and may have experienced a ceiling effect that limited potential gains in strength and power with this particular training protocol. In the study by Hakkinen et al. the women appeared to make the majority of their gains in maximal knee extensor torque in the first eight weeks (same duration as this study) with a plateau in performance from 2 to 6 months. Interestingly, the maximal knee extensor torque seen in that study after six months of training $\left(\approx 2.0 \mathrm{Nm} \cdot \mathrm{kg}^{-1}\right)$ was very similar to the peak knee extensor 
torque seen in our NR after eight weeks of training $\left(1.95 \mathrm{Nm} \cdot \mathrm{kg}^{-1}\right)$. Another possible explanation of the lack of response is that as the training program moved from the summer to late fall and winter months, decreased habitual activity may have contributed to the lack of strength and power gains in NR [23].

The rate of nervous drive to the muscle during the rapid application of force was lower at baseline in the R suggesting lower motor unit recruitment and firing rates prior to training [25]. There were no differences in the level of antagonist coactivation between groups that could explain the lower force and power outputs of the $\mathrm{R}$ prior to training or the lack of response to training in NR. Concurrent with increases in strength and power, $\mathrm{R}$ demonstrated increased neural drive to the muscle following training that may partially explain the improved muscle performance.

In conclusion, reduced muscle tissue mass and contractility, coupled with reduced neural drive to muscle, likely explain the large deficit in baseline strength and power seen in those that respond well to resistance training. In response to the particular training program used in this study, older women who already possess muscle performance that exceeds that of their peers seem to have a lower capacity for improvement than women who have low initial levels of performance. The resistance training protocol used only shortening (concentric), isokinetic contractions that may have been an insufficient stimulus for the high-functioning women, therefore high-functioning seniors may benefit from more aggressive training programs. Examples may include the use of exercises with a lengthening (eccentric) component; beginning plyometric jumping exercises on a compliant surface; high velocity / low load isotonic exercise using either machine weight, free weight, or wind loaded resistance; or medicine ball exercises focused on explosive power. Following successful completion of a beginning resistance program, high-functioning seniors may also benefit from resistance training that aims to increase peak muscle strength and power by including lower repetition, higher weight exercises. Given proper time for adaptation, correct form and close supervision, healthy, older adults are well equipped to make significant gains in muscle strength and power.

\section{Acknowledgments}

This publication was made possible by the Vermont Genetics Network through Grant Number P20 RR16462 from the INBRE Program of the National Center for Research Resources (NCRR), a component of the National Institutes of Health (NIH). Its contents are solely the responsibility of the authors and do not necessarily represent the official views of NCRR or NIH.

\section{References}

[1]. AGS. Guideline for the prevention of falls in older persons. American Geriatrics Society, British Geriatrics Society, and American Academy of Orthopaedic Surgeons Panel on Falls Prevention. J Am Geriatr Soc 2001;49:664-672. [PubMed: 11380764]

[2]. Ainsworth BE, Haskell WL, Leon AS, Jacobs DR Jr. Montoye HJ, Sallis JF, et al. Compendium of physical activities: classification of energy costs of human physical activities. Med Sci Sports Exerc 1993;25:71-80. [PubMed: 8292105]

[3]. Bassey EJ, Fiatarone MA, O'Neill EF, Kelly M, Evans WJ, Lipsitz LA. Leg extensor power and functional performance in very old men and women. Clin Sci (Lond) 1992;82:321-327. [PubMed: 1312417]

[4]. Bean JF, Kiely DK, Herman S, Leveille SG, Mizer K, Frontera WR, et al. The relationship between leg power and physical performance in mobility-limited older people. J Am Geriatr Soc 2002;50:461-467. [PubMed: 11943041]

[5]. Brunner F, Schmid A, Sheikhzadeh A, Nordin M, Yoon J, Frankel V. Effects of aging on Type II muscle fibers: a systematic review of the literature. J Aging Phys Act 2007;15:336-348. [PubMed: 17724398] 
[6]. Earles DR, Judge JO, Gunnarsson OT. Velocity training induces power-specific adaptations in highly functioning older adults. Arch Phys Med Rehabil 2001;82:872-878. [PubMed: 11441371]

[7]. Ferri A, Scaglioni G, Pousson M, Capodaglio P, Van Hoecke J, Narici MV. Strength and power changes of the human plantar flexors and knee extensors in response to resistance training in old age. Acta Physiol Scand 2003;177:69-78. [PubMed: 12492780]

[8]. Hakkinen K, Kraemer WJ, Newton RU, Alen M. Changes in electromyographic activity, muscle fibre and force production characteristics during heavy resistance/power strength training in middleaged and older men and women. Acta Physiol Scand 2001;171:51-62. [PubMed: 11350263]

[9]. Hakkinen K, Newton RU, Gordon SE, McCormick M, Volek JS, Nindl BC, et al. Changes in muscle morphology, electromyographic activity, and force production characteristics during progressive strength training in young and older men. J Gerontol A Biol Sci Med Sci 1998;53:B415-B423. [PubMed: 9823737]

[10]. Hakkinen K, Pakarinen A, Kraemer WJ, Hakkinen A, Valkeinen H, Alen M. Selective muscle hypertrophy, changes in EMG and force, and serum hormones during strength training in older women. J Appl Physiol 2001;91:569-580. [PubMed: 11457767]

[11]. Kaczor JJ, Ziolkowski W, Antosiewicz J, Hac S, Tarnopolsky MA, Popinigis J. The effect of aging on anaerobic and aerobic enzyme activities in human skeletal muscle. J Gerontol A Biol Sci Med Sci 2006;61:339-344. [PubMed: 16611699]

[12]. Kostka T. Quadriceps maximal power and optimal shortening velocity in 335 men aged 23-88 years. Eur J Appl Physiol 2005;95:140-145. [PubMed: 16032419]

[13]. Kriska AM, Knowler WC, LaPorte RE, Drash AL, Wing RR, Blair SN, et al. Development of questionnaire to examine relationship of physical activity and diabetes in Pima Indians. Diabetes Care 1990;13:401-411. [PubMed: 2318100]

[14]. LaRoche DP, Knight CA, Dickie JL, Lussier MV, Roy SJ. Explosive Force and Fractionated Reaction Time in Elderly Low and High Active Women. Med Sci Sports Exerc 2007;39:1659_ 1665. [PubMed: 17805100]

[15]. LaRoche DP, Roy S, Knight CA, Dickie J. Elderly women have blunted response to resistance training despite reduced antagonist coactivation. Medicine \& Science in Sports \& Exercise 2008;40

[16]. Magnusson SP, Simonsen EB, Aagaard P, Boesen J, Johannsen F, Kjaer M. Determinants of musculoskeletal flexibility: viscoelastic properties, cross-sectional area, EMG and stretch tolerance. Scand J Med Sci Sports 1997;7:195-202. [PubMed: 9241023]

[17]. Narayanan N, Jones DL, Xu A, Yu JC. Effects of aging on sarcoplasmic reticulum function and contraction duration in skeletal muscles of the rat. Am J Physiol 1996;271:C1032-C1040. [PubMed: 8897807]

[18]. Narici M, Kayser B, Barattini P, Cerretelli P. Effects of 17-day spaceflight on electrically evoked torque and cross-sectional area of the human triceps surae. Eur J Appl Physiol 2003;90:275-282. [PubMed: 13680242]

[19]. Newton RU, Hakkinen K, Hakkinen A, McCormick M, Volek J, Kraemer WJ. Mixed-methods resistance training increases power and strength of young and older men. Med Sci Sports Exerc 2002;34:1367-1375. [PubMed: 12165694]

[20]. Ortenblad N, Lunde PK, Levin K, Andersen JL, Pedersen PK. Enhanced sarcoplasmic reticulum $\mathrm{Ca}(2+)$ release following intermittent sprint training. Am J Physiol Regul Integr Comp Physiol 2000;279:R152-R160. [PubMed: 10896877]

[21]. Pastoris O, Boschi F, Verri M, Baiardi P, Felzani G, Vecchiet J, et al. The effects of aging on enzyme activities and metabolite concentrations in skeletal muscle from sedentary male and female subjects. Exp Gerontol 2000;35:95-104. [PubMed: 10705043]

[22]. Petrella JK, Miller LS, Cress ME. Leg extensor power, cognition, and functional performance in independent and marginally dependent older adults. Age Ageing 2004;33:342-348. [PubMed: 15082417]

[23]. Pivarnik JM, Reeves MJ, Rafferty AP. Seasonal variation in adult leisure-time physical activity. Med Sci Sports Exerc 2003;35:1004-1008. [PubMed: 12783049]

[24]. Prochniewicz E, Thomas DD, Thompson LV. Age-related decline in actomyosin function. J Gerontol A Biol Sci Med Sci 2005;60:425-431. [PubMed: 15933379] 
[25]. Sale DG. Influence of exercise and training on motor unit activation. Exerc Sport Sci Rev 1987;15:95-151. [PubMed: 3297731]

[26]. Skelton DA, Young A, Greig CA, Malbut KE. Effects of resistance training on strength, power, and selected functional abilities of women aged 75 and older. J Am Geriatr Soc 1995;43:1081-1087. [PubMed: 7560695]

[27]. Symons TB, Vandervoort AA, Rice CL, Overend TJ, Marsh GD. Effects of maximal isometric and isokinetic resistance training on strength and functional mobility in older adults. J Gerontol A Biol Sci Med Sci 2005;60:777-781. [PubMed: 15983182]

[28]. Thelen DG, Schultz AB, Alexander NB, Ashton-Miller JA. Effects of age on rapid ankle torque development. J Gerontol A Biol Sci Med Sci 1996;51:M226-M232. [PubMed: 8808994]

[29]. Winters-Hart CS, Brach JS, Storti KL, Trauth JM, Kriska AM. Validity of a questionnaire to assess historical physical activity in older women. Med Sci Sports Exerc 2004;36:2082-2087. [PubMed: 15570143] 

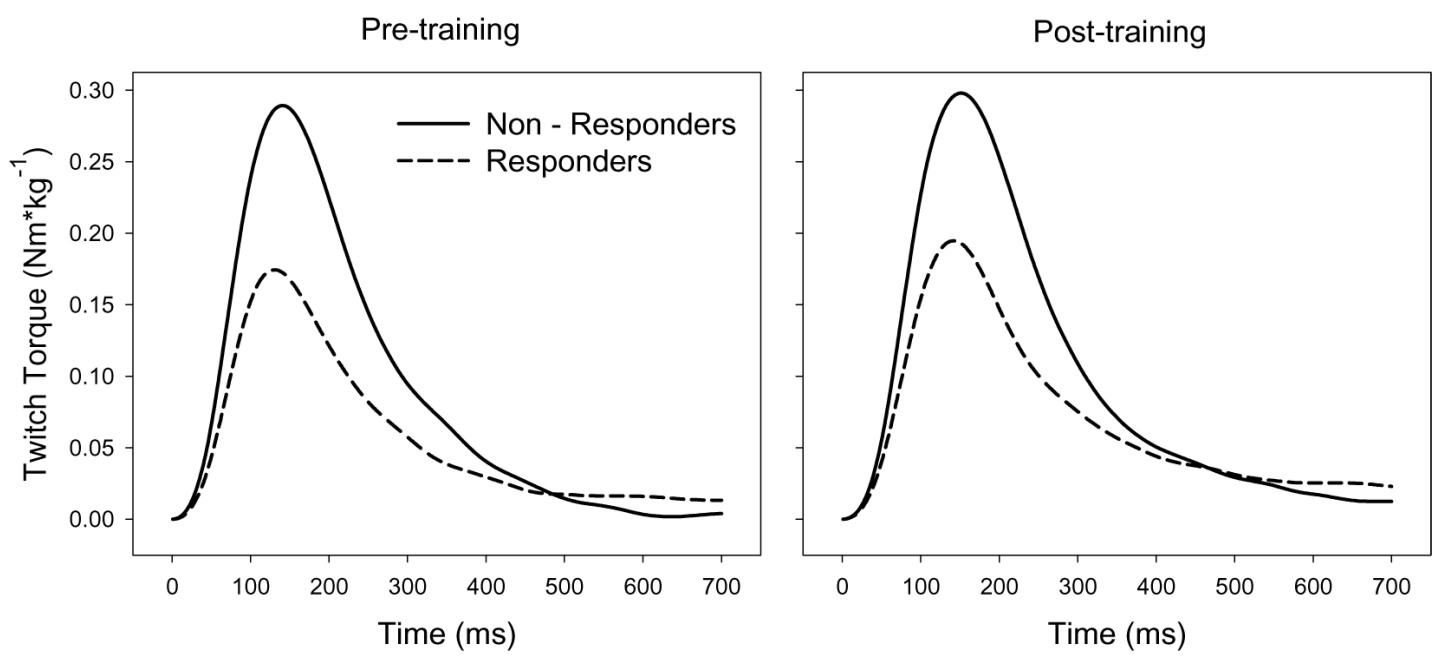

Fig. 1.

Comparison of group means for electrically evoked maximal muscle twitches of the knee extensors, between responders and nonresponders, both before and after muscle power training. 

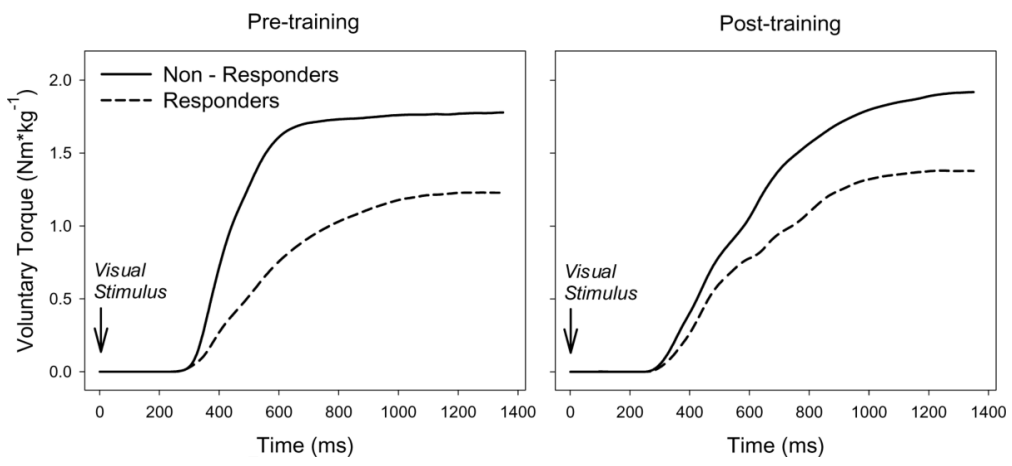

Fig. 2.

Comparison of group means for the rate and magnitude of voluntary knee extensor torque, between responders and nonresponders, both before and after muscle power training. 

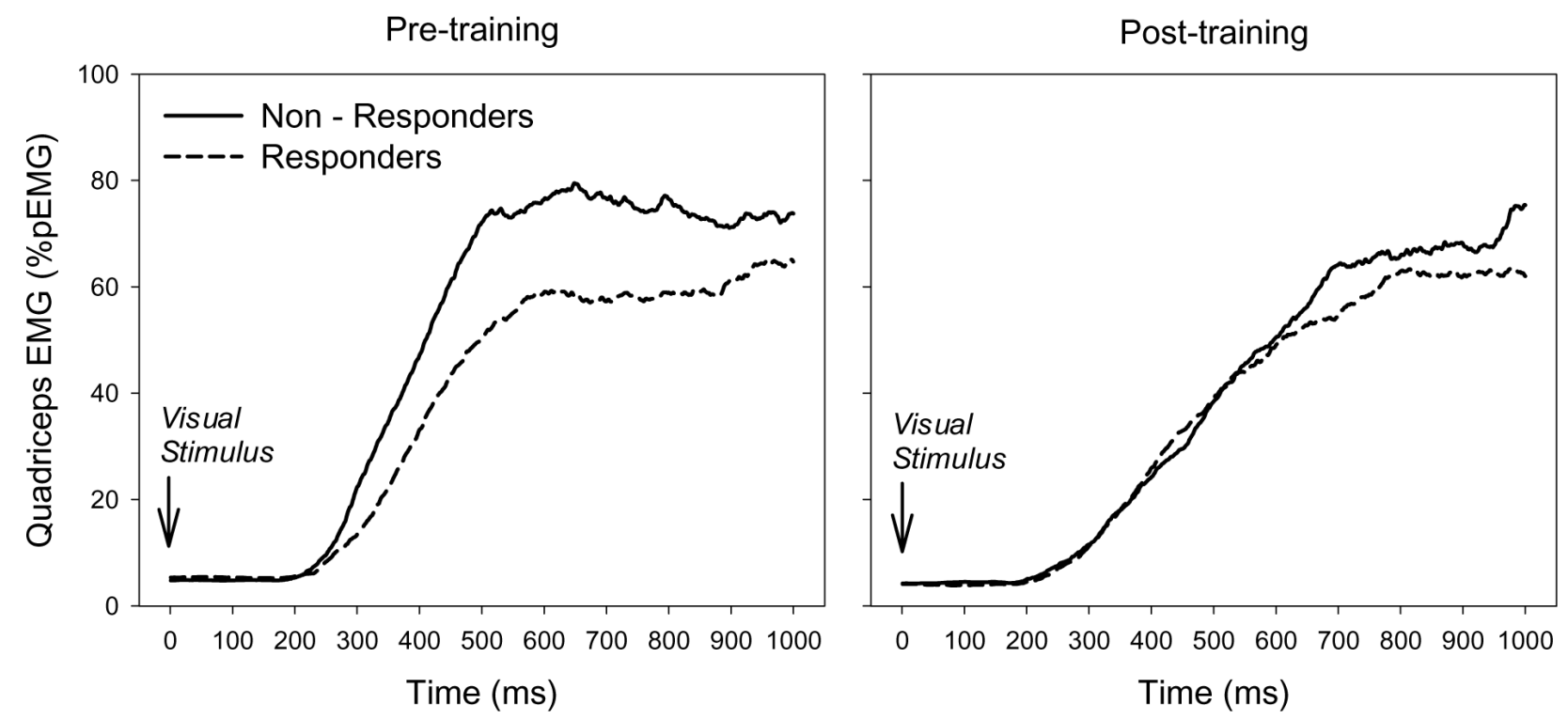

Fig. 3.

Comparison of the group means for rate and magnitude of nervous activation of the knee extensors, between responders and nonresponders, both before and after muscle power training. 


\section{Table 1}

Subject descriptive characteristics.

\begin{tabular}{lcc}
\hline & Responders $\boldsymbol{n}=\mathbf{6}$ & Non-Responders $\boldsymbol{n}=\mathbf{6}$ \\
\hline Age $(\mathrm{yr})$ & $73.0 \pm 7.2$ & $69.7 \pm 5.2$ \\
Mass $(\mathrm{kg})$ & $76.1 \pm 4.8$ & $70.9 \pm 8.2$ \\
Height $(\mathrm{cm})$ & $158.5 \pm 3.3$ & $159.8 \pm 4.6$ \\
Body Mass Index $\left(\mathrm{kg} \cdot \mathrm{m}^{-2}\right.$ ) & $30.3 \pm 1.5$ & $27.8 \pm 3.2$ \\
Number of Health Complications & $2.2 \pm 1.6$ & $1.5 \pm 1.5$ \\
Weekly Physical Activity (MET $\cdot$ hours $\cdot$ week $^{-1}$ ) & $24.3 \pm 16.9$ & $18.3 \pm 11.7$ \\
Weekly Aerobic Activity (MET $\cdot$ hours $\cdot$ week $^{-1}$ ) & $17.8 \pm 15.4$ & $18.3 \pm 11.7$ \\
Weekly Strength Activity (MET $\cdot$ hours $\cdot$ week $^{-1}$ ) & $6.4 \pm 13.8$ & $0 \pm 0$ \\
\hline
\end{tabular}

Number of Health Complications $=$ the total current prevalence ( score of $0=$ best health, score of $11=$ worst health) of the following conditions: heart disease, cerebral vascular accident, hypertension, osteoporosis, arthritis, joint replacement, ligamentous injury, diabetes, peripheral vascular disease, peripheral neuropathy, and prescription medication use. Values are mean $\pm \mathrm{SD}$ 


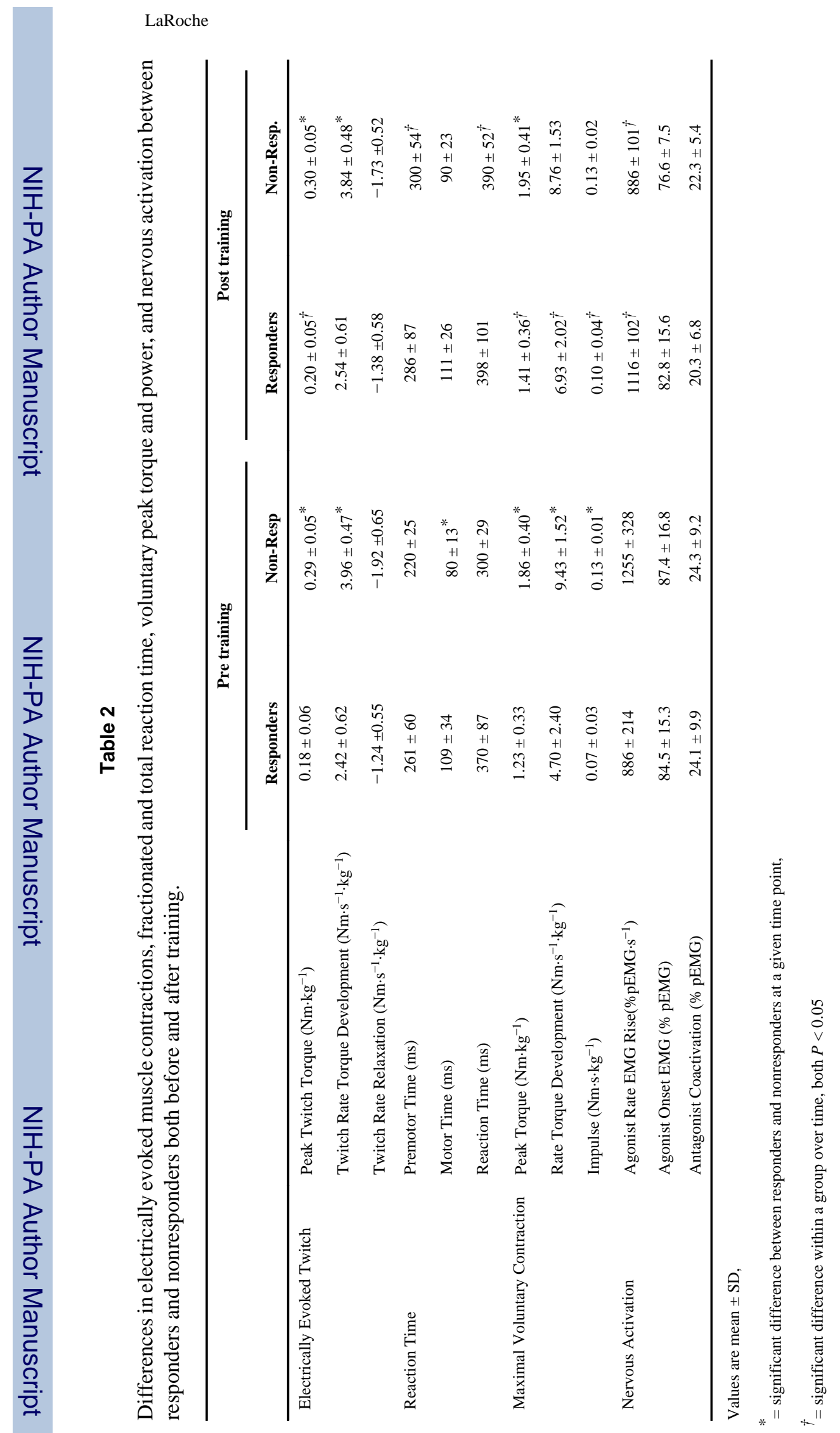

Page 14 